\title{
Impact of juvenile idiopathic arthritis on schooling
}

\author{
Ilham Bouaddi ${ }^{1 *}$, Samira Rostom ${ }^{1}$, Dalal El Badri ${ }^{1}$, Asmae Hassani ${ }^{1}$, Bouchra Chkirate ${ }^{2}$, Bouchra Amine ${ }^{1}$ \\ and Najia Hajjaj-Hassouni ${ }^{1}$
}

\begin{abstract}
Background: Juvenile idiopathic arthritis (JIA) is the most common arthropathy of childhood. Different diseases affect school attendance to varying degrees. The aim of this study was to assess the impact of juvenile idiopathic arthritis (JIA) on Moroccan children's schooling.

Methods: Thirty-three children with JIA were included in this study, having been previously diagnosed according to the classification criteria of the International League of Associations for Rheumatology (ILAR). Seventy-four healthy children were recruited to serve as controls. Data was obtained for all children on their school level, educational performance, and attendance. The rate of absenteeism due to health complications was noted.

Results: All healthy children were able to attend school $(p<0.0001)$, while $33 \%$ of children with JIA were unable to attend school due to their condition. The students with JIA who were able to attend school were absent much more often than controls (63\% compared to $20 \%)$, with a highly significant $p$ value $(p<0.0001)$. Slightly less than half of the JIA patients (48.5\%) failed in their schooling. In univariate analysis, there was an association between absenteeism and tender joints ( $p=0.02)$, disease activity score (DAS28) ( $p=0.007)$, Childhood Health Assessment Questionnaire (CHAQ) $(p=0.01)$, and erythrocyte sedimentation rate (ESR) $(p=0.03)$. In multivariate analysis, the only association persisted between DAS28 and absenteeism.
\end{abstract}

Conclusions: Our study suggested that the schooling of children with JIA was negatively impacted due to the disorder. More studies, with a larger sample of children, are needed to confirm our findings.

Keywords: Juvenile idiopathic arthritis, Children, Healthy controls, School, Absenteeism, Failure

\section{Background}

Juvenile idiopathic arthritis (JIA) is the most common arthropathy of childhood, with an estimated prevalence between 7 and 400 for every 100,000 children [1]. It can persist over many years and can also lead to disability and dysfunction in adulthood [2]. JIA is a heterogeneous, multifactorial autoimmune disease characterized by persistent joint inflammation, which manifests as swelling, pain, and limitation of movement [3]. The disease can also lead to physical disability and reduced quality of life [4]. Different diseases affect school attendance to varying degrees, and there are indications that chronic arthritis is particularly disruptive because of marked pain, malaise

\footnotetext{
* Correspondence: drbouaddilham@yahoo.fr

'Department of Rheumatology, Al Ayachi Hospital, University Hospital of Rabat-Salé, Salé 11000, Morocco

Full list of author information is available at the end of the article
}

and physical restriction; therefore, the potential for school disruption is high, particularly in severely affected children [5]. Due to prolonged and/or frequent absences, children with chronic health impairments are often confronted with educational difficulties [6]. Missing school can lead to problems in keeping up with schoolwork and social relationships [7], and a prolonged absence or multiple brief absences from school may contribute significantly to negative school performance [8]. Several researchers have observed negative correlations between absenteeism (for all reasons, including illness) and academic performance $[9,10]$. Frequent absences from school, and thus a lack of involvement in school activities, may limit opportunities for children to establish friendships and result in increased passivity and the development of feelings of inferiority [11]. Students who are absent must compensate for potential educational
C Biomed Central 
disadvantages by making up assignments and utilizing home- or hospital-based educational services [12]. Increased absenteeism has been documented for a number of conditions, such as asthma, diabetes, epilepsy and hemophilia [13]. The Moroccan educational system consists of three sub-systems: subsystem school with preschool, primary, secondary and post secondary, the subsystem of higher education and the subsystem of Literacy and Non-formal Education. However, to the best of our knowledge, there is no data on Arab and/or African children with JIA concerning education. The aim of our study was to assess the impact of JIA on Moroccan children's schooling.

\section{Methods}

Our study group included 33 children with JIA who met the classification criteria set by the International League of Associations for Rheumatology (ILAR) [14]. These children were patients of the Departments of Rheumatology and/or Pediatrics of the University Hospital of Rabat-Salé. Both departments carried out this cross-sectional study. Children were from to the region of Rabat-Sale. Any patient with a chronic disease, in addition to JIA, that would influence the child's schooling was excluded. Children (patients and controls) less than 5 years were not included because these younger children wouldn't be expected to be in school.

The Ethics Committee of our hospital approved this study and all participants' parents provided written consent.

A detailed questionnaire was completed for each participant by interviewing them or their parents as well as by information obtained from their medical records. Collected data included age, sex, subtype of JIA, disease duration and level of disability according to the Childhood Heath Assessment Questionnaire (CHAQ)(translated and certified in Arabic) [15]. Health status was evaluated by collecting the patient's assessment of pain by [visual analogue scale (VAS) $0-10 \mathrm{~cm}$ ]. The severity of JIA was assessed using the following: disease activity score (DAS28) [16,17] for polyarticular and oligoarticular JIA; Bath AS Disease Activity Index (BASDAI) (translated and certified in Arabic) for juvenile spondylarthropathy [18]; patient assessment of pain and global disease activity; physician assessment of global disease activity; erythrocyte sedimentation rate (ESR) and Creactive protein (CRP). Medications used for JIA treatment were documented. No patient received biotherapy. This is due to the lack of social security and in Morocco only infliximab is reimbursable.

\section{Schooling}

To assess school performance, we asked parents to indicate the child's educational level (illiterate, primary, middle or high school) and whether or not they were currently attending school; if the child had stopped attending school, then the cause of abandonment. The number of days over the previous academic year that the child had been absent due to JIA was collected and was then measured as percentage. School failure was defined by whether the child had had to repeat a year of schooling. School level of mothers was included.

\section{Controls}

The control group consisted of 74 children with similar age and gender to the study group. They were selected from children who had been patients in our hospital. Children with chronic diseases were excluded from the control group. They underwent physical examination and demographic characteristics were noted. Details concerning school attendance and performance were also collected. Information about the mothers of the control patients was not elicited.

\section{Statistical analysis}

Analyses were performed using the software program SPSS for Windows (Version 13.0, SPSS Inc, Chicago, IL). Descriptive statistics were used to assess the demographic variables and characteristics of schooling. A linear regression was used to analyze the association between days absent from school and characteristics of disease (duration of disease, subtype, disease activity, and $\mathrm{CHAQ}$ ). The Chi Square was used to compare school attendance, absenteeism and school failure of the JIA patients and healthy controls. P values less than 0.05 were considered significant.

\section{Results}

\section{Characteristics of the study patients}

33 patients with JIA were included, of whom 18 (54\%) were male in this cross-sectional study. The median age was 11 years [5.75-14]. The median disease duration was 2 years [1-4.5]. The most common subtype was rheumatoid factor-positive polyarthritis $(45.5 \%)$ followed by systematic (27.5\%) and oligoarticular (22.5\%). The mean DAS28 was $5.33 \pm 1.11$. The median $\mathrm{CHAQ}$ was 0.5 [0-1.61]. More than half of the children (58\%) were receiving corticosteroid. Disease-modifying antirheumatic drugs (DMARDs) were used by 17 of the 33 patients (methotrexate $[n=12]$, sulfasalazine $[n=5]$ ). Patients' characteristics are presented in Table 1.

\section{Characteristics of patients' schooling}

Sixty-seven percent of JIA patients were able to attend school while $12 \%$ had to stop their schooling and $21 \%$ were illiterate because of their illness (Figure 1). A year of schooling was repeated by $48.5 \%$ of patients. The median absenteeism rate was $2 \%$ [0-6]. 
Table 1 Socio-demographic and clinical characteristics of the patients

\begin{tabular}{|c|c|}
\hline Female sex ${ }^{1}$ & $15(45.5)$ \\
\hline Age $(\text { years })^{2}$ & $11[5.75-14]$ \\
\hline \multicolumn{2}{|l|}{ Subtype of $A J^{1}$} \\
\hline Systemic-onset arthritis & $8(24.2)$ \\
\hline Oligoarthritis & $4(12.1)$ \\
\hline Rheumatoid factor- positive polyarthritis & 15(45.5) \\
\hline Rheumatoid factor- negative polyarthritis & $1(2.5)$ \\
\hline Enthesitis-related arthritis & $5(15.2)$ \\
\hline DAS $28^{3}$ & $5.33 \pm 1.11$ \\
\hline $\mathrm{CHAQ}^{2}$ & $0.5[0-1.61]$ \\
\hline BASDAI $^{2}$ & $0.7[0-2.75]$ \\
\hline ACPA Positive ${ }^{1}$ & $5(15.2)$ \\
\hline Rheumatoid factor positive (RF) ${ }^{1}$ & $4(12.1)$ \\
\hline Antinuclear antibodies positive $^{1}$ & $25(76)$ \\
\hline $\operatorname{ESR}(\mathrm{mm} / \mathrm{h})^{2}$ & $35[25-50.5]$ \\
\hline $\mathrm{CRP}\left(\mathrm{mg} / \mathrm{l}^{2}\right.$ & $20[10.5-40]$ \\
\hline \multicolumn{2}{|l|}{ Medications used: } \\
\hline NSAID ${ }^{1}$ & $26(79)$ \\
\hline Corticosteroid $^{1}$ & 19(58) \\
\hline Methotrexate $^{1}$ & 12(36.4) \\
\hline sulfasalazine ${ }^{1}$ & $5(15.2)$ \\
\hline \multicolumn{2}{|l|}{ case-control: } \\
\hline Female sex ${ }^{1}$ & $33(45)$ \\
\hline Age $(\text { years) })^{2}$ & $10[6-14]$ \\
\hline
\end{tabular}

1: Number and percentage $\mathrm{N}(\%)$; : median and interquartile range IQR; 3 : mean and standard deviation; DAS: disease activity score; CHAQ: Childhood Health Assessment Questionnaire; ESR: Erythrocyte sedimentation rate; CRP: Creactive protein, ACPA: Anti-citrullinated peptides antibodies; NSAID: nonsteroidal anti-inflammatory drugs; BASDAl: Bath AS Disease Activity Index.

Variables associated with absenteeism and school failure In univariate analysis, there was an association between absenteeism and tender joints $(\mathrm{p}=0.02)$, DAS28 ( $\mathrm{p}=$ $0.007)$, ESR $(p=0.03)$ and CHAQ $(p=0.01)$. In multivariate analysis, a positive association existed between DAS28 and absenteeism (Table 2). School absence was

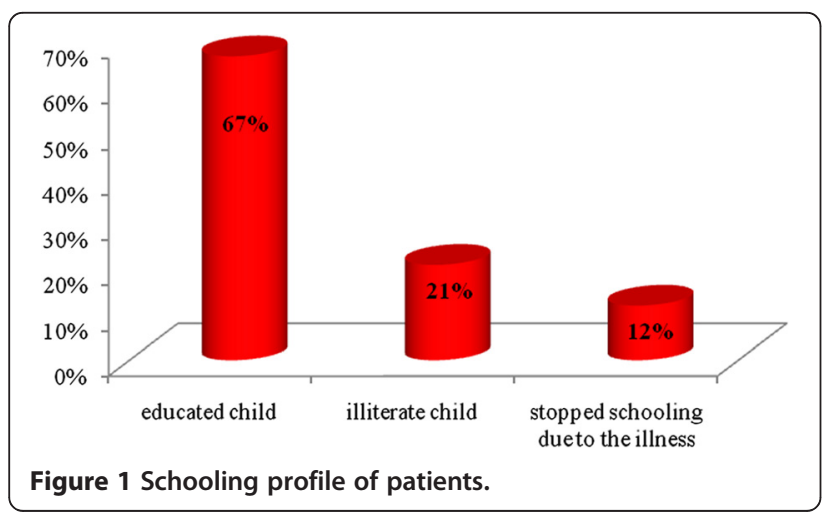

not significantly associated with age, JIA subtype, duration of illness, treatment and/or swollen joints (Table 2). $51.5 \%$ of mothers were illiterate. $81 \%$ of children, who had failed in their schooling, their moms were illiterate. The failure of children in school was significantly linked to illiterate mothers $(\mathrm{p}=0.001)$. There were no association between school failure and $\operatorname{sex}(\mathrm{p}=0.6)$.

\section{Characteristics of controls' schooling}

The median age was 10 years [6-14] and all children attended school. No child in this population had to repeat a year of schooling. The median absenteeism rate was $0.68 \%$ [0.68-1.02].

\section{Comparison between patients and healthy controls}

Only $67 \%$ children having JIA attended school while all healthy children did $(\mathrm{p}<0.0001)$. Those children with JIA who did attend school were absent much more often than the control $(63 \%$ compared to $20 \%)(\mathrm{p}<0.0001)$, and $48.5 \%$ of patients failed in their schooling $(\mathrm{p}<$ $0.001)$. Twelve percent of patients stopped their education because of the disease versus $0 \%$ for controls $(\mathrm{p}<$ 0.0001) (Table 3).

\section{Discussion}

The main objective of this study was to determine the impact of JIA on Moroccan children's schooling. Our study showed that JIA negatively affects schooling. All healthy controls were able to attend school, compared to $33 \%$ of patients with JIA who were unable to do so. For a child with a chronic disease, such as JIA, the school environment may be fraught with problems [19-22]. Two studies noted that in academic achievement, chronically ill school-age children perform below their peers [21,22].

Our study showed that the percentage of patients with JIA who left school was high compared to the healthy controls, and in addition they missed more school days per year. Sturge et al. found that children with JIA had an overall mean school attendance rate of 92\% (equivalent to 15 days absent per year), which was comparable to rates described in another study of children with a chronic physical illness such as asthma [23]. Barbara et al. studied children with a chronic illness, and found that the mean number of days absent was 16.9 and the mean percentage of days absent was 9.4\% [24]. There is evidence suggesting that absenteeism plays a large role in determining students' achievement on both standardized tests and classroom performance, which our work further supports [25]. A study of boys with hemophilia/ HIV disease conducted by Indiana State University assessed the effects of absenteeism on cognitive skills index and various achievement indicators and found that Hemophilia may be a risk factor for academic underachievement [26]. In our study, almost half of the 
Table 2 Variables associated with absenteeism

\begin{tabular}{|c|c|c|c|c|c|c|}
\hline & & ivariate anal & & & tivariate ana & \\
\hline & $B$ & $I C_{95 \%}$ & $P$ & $B$ & $I C_{95 \%}$ & $P$ \\
\hline Age (year) & 0.24 & {$[-0.36-1.48]$} & 0.22 & & & \\
\hline Subtype of JIA & -0.03 & {$[-4.65-4.01]$} & 0.8 & & & \\
\hline Duration of disease (year) & 0.28 & {$[-0.45-2.88]$} & 0.14 & & & \\
\hline Tender joints & 0.44 & {$[0.13-1.57]$} & 0.02 & -0.75 & {$[-1.89-0.48]$} & 0.2 \\
\hline Swelling joints & 0.29 & {$[-0.37-2.48]$} & 0.14 & & & \\
\hline $\operatorname{ESR}(\mathrm{mm} / \mathrm{h})$ & 0.41 & {$[0.01-0.38]$} & 0.03 & -0.70 & {$[-0.48-0.12]$} & 0.2 \\
\hline CRP (mg/l) & 0.27 & {$[-0.06-0.35]$} & 0.16 & & & \\
\hline DAS28 & 0.70 & {$[0.93-4.63]$} & 0.007 & 1.91 & {$[0.61-14.47]$} & 0.03 \\
\hline BASDAI & -0.18 & {$[-0.28-0.20]$} & 0.6 & & & \\
\hline $\mathrm{CHAQ}$ & 0.44 & [0.80-8.14] & 0.01 & 0.29 & {$[-1.41-4.39]$} & 0.2 \\
\hline
\end{tabular}

DAS, disease activity score; CHAQ, Childhood Health Assessment Questionnaire; ESR, Erythrocyte sedimentation rate; CRP, C-reactive protein; BASDAI, Bath AS Disease Activity Index.

children with JIA (48.5\%) had failed in their schooling, while this percentage was zero for healthy controls $(\mathrm{p}<$ 0.0001). Children and adolescents with chronic illness experience more academic difficulty than their healthy peers [27]. In a different study, $45 \%$ of students with chronic illness reported falling behind in their schoolwork, which lead them to dislike school [28]. Our study showed that children's failure at school was significantly associated with illiterate mothers $(\mathrm{p}=0.001)$. This can be explained by the fact that parents who did not complete school may place less value on education and school attendance. Only the parents' education emerged as a possible protective factor [29]. The parents' education may act as a proxy indicator of the value families place on education, the expectations they have for academic achievement, and/or a genetic predisposition for academic achievement [29].

Additionally, chronic absenteeism would affect the child's ability to cope with their illness because it would interfere with the child learning the necessary skills to achieve a productive life [24]. We established that disease activity and CHAQ were the two significant factors that predicted the number of days missed from school in univariate analysis. In the study by Sturge et al., a small group of four children (all suffering from the more severe poly illness type) had missed a great deal of

Table 3 Comparison between patients and healthy controls

\begin{tabular}{lccc}
\hline & Healthy controls & JIA & $\mathbf{p}$ \\
\hline Schooling & $100 \%$ & $67 \%$ & $<\mathbf{0 . 0 0 0 1}$ \\
Absenteeism & $20 \%$ & $63 \%$ & $<\mathbf{0 . 0 0 0 1}$ \\
Schooling failure & $0 \%$ & $48.5 \%$ & $<\mathbf{0 . 0 0 0 1}$ \\
The school stop & $0 \%$ & $12 \%$ & $<\mathbf{0 . 0 0 0 1}$ \\
\hline
\end{tabular}

schooling (between a quarter and a half of the time) and nine (or about one in 10 of the whole group) had missed $>20 \%$ of the time (39 days) [7]. As in previous studies with ill children [5,23,30-32], Sturge et al. found that attendance was linked to the severity of illness, in as much as this can be ascertained through type of illness (pauciand polyarthritis), and was more compromised in the poly- group. We, however, didn't find an association with absenteeism and each specific subtype of JIA. Our study showed that there is a positive association with absenteeism and CHAQ. Miller et al. completed a retrospective study where school age children with JIA (with and without manifest synovitis) were compared with healthy controls. He reported the loss of physical functioning (CHAQ) at between $10 \%$ and $65 \%$ [33]. If the child's hands were affected, simple things such holding a pencil or writing for extended periods of time would be painful, making it more difficult to complete class work in a timely manner [33].

Despite the methodological limitations of this study (cross-sectional, single-center), this study has two strengths absence of information about the mothers of the control patients. First, it could support the few studies concerning the schooling of children with JIA. Second, this study is the first one performed in an Arab and/or African country.

\section{Conclusions}

Our study suggests that children's schooling is affected by JIA. Disease activity and functional impairment seem to influence the school level of children, hence the importance of proper management of these patients to increase their academic performance. Additional research, with a larger sample of children, is needed to confirm our findings. 


\section{Competing interest}

The authors declare that they have no conflict of interest.

\section{Authors' contributions}

N. Hajjaj-Hassouni, B. Amine, S. Rostom: correction section of the article. D. El Badri, A. Hassani, B. Chkirate: collection of patients and fill the questionnaire All authors read and approved the final manuscript.

\section{Author details}

${ }^{1}$ Department of Rheumatology, Al Ayachi Hospital, University Hospital of Rabat-Salé, Salé 11000, Morocco. ²Department of Pediatrics, Children's Hospital, University Hospital of Rabat-Salé, Rabat 10000, Morocco.

\section{Received: 2 July 2012 Accepted: 26 December 2012}

Published: 7 January 2013

\section{References}

1. Olson JC: Juvenile idiopathic arthritis: an update. WMJ 2003, 102:45-50.

2. Gare BA, Fasth A: The natural history of juvenile chronic arthritis: a population based cohort study. II. Outcome. J Rheumatol 1995, 22:308-319.

3. Weiss JE, llowite NT: Juvenile Idiopathic Arthritis. Pediatr Clin North Am 2005, 52(2):413-442.

4. Gutiérrez-Suárez R, Pistotrio A, Cespedes-Cruz A, Noroambuena X, Flato B, Rumba I, Harjacek J, Nielsen S, Susic G, Mihaylova D, Huemer C, MeloGomes J, Andersson-Gare B, Balogh Z, De Cunto C, Vesely R, Pagava K, Romicka AM, Burgos-Varga R, Martinin A, Ruperto N: For the Pediatric Rheumatology International Trials Organization (PRINTO): Health related quality of life of patients with juvenile idiopathic arthritis coming from 3 different geographic areas. The PRINTO multinational quality of life cohort study. Rheum 2007, 46:314-320.

5. Fowler MG, Johnson MP, Atkinson SS: School achievement and absence in children with chronic health conditions. J Pediatr 1985, 106:683-687.

6. Newacheck P, Taylor W: Childhood chronic illness: prevalence, severity, and impact. Am J Public Health 1992, 82:364-371.

7. Sturge C, Garralda ME, Boissin M, Dore CJ, Woo P: School attendance and juvenile chronic arthritis. Br J Rheumatol 1997, 36(11):1218-1223.

8. Sexson S, Madan-Swain A: School reentry for the child with chronic illness. J Learn Disabil 1993, 26(2):115-125

9. Freudenberg N, Feldman C, Clark N: The impact of bronchial asthma on school attendance and performance. J Sch Health 1980, 50:522-526.

10. Fowler M, Davenport M, Garg R: School functioning of US children with asthma. Pediatrics 1992, 90:939-944.

11. Chann E, Piira T, Betts G: The school functioning of children with chronic and recurrent pain. Pediatr Pain Lett. 2005, 7:11-14.

12. Weitzman M: What we have not learned and what we know about excessive school absence and school dropout. J Dev Behav Pediatr 1992 13(1):55-57.

13. Eiser C: Growing up with a chronic disease. London: Kingsley; 1993.

14. Petty RE, Southwood TR, Manners P, et al: International League of Associations for Rheumatology classification of juvenile idiopathic arthritis: second revision, Edmonton, 2001. J Rheumatol 2004, 31(2):390-392

15. Rostom S, Amine B, Bensabbah R, Chkirat B, Abouqal R, Hajjaj-Hassouni N: Psychometric properties evaluation of the childhood health assessment questionnaire (CHAQ) in Moroccan juvenile idiopathic arthritis. Rheumatol Int 2010, 30(7):879-885.

16. Ringold $S$, Chon $Y$, Singer NG: Associations between the American College of Rheumatology pediatric response measures and the continuous measures of disease activity used in adult rheumatoid arthritis. Arthritis Rheum 2009, 60(12):3776-3783.

17. Lurati A, Pontikaki I, Teruzzi B, Desiati F, Gerloni V, Gattinara M, Cimaz R, Fantini F: A comparison of response criteria to evaluate therapeutic response in patients with juvenile idiopathic arthritis treated with methotrexate and/or anti-tumor necrosis factor alpha agents. Arthritis Rheum 2006, 54(5):1602-1607.

18. Viswanath $V$, Myles A, Dayal R, Aggarwal A: Levels of serum matrix metalloproteinase-3 correlate with disease activity in the enthesitisrelated arthritis category of juvenile idiopathic arthritis. J Rheumatol 2011 38(11):2482-2487.
19. Haggerty RJ, Roghmann KJ, Pless IB: Child Health and the Community. New York: John Wiley and Sons; 1975:78-94.

20. Pless IB, Pinkerton P: Chronic childhood disorders: promoting patterns of adjustment. Chicago: Year Book Medical Publishers, Inc; 1975:59-86.

21. Pless IB, Roghmann KJ: Chronic illness and its consequences: observations based on three epidemiologic surveys. J Pediatr 1971, 79:351-359.

22. Sultz HA, Schlessinger ER, Mashier WC, et al: Long-term childhood illness. Pittsburgh: University of Pittsburgh Press; 1972:351-359. 89-141.

23. Parcel GS, Gilman SC, Nader PR, Bunce H: A comparison of absentee rates of elementary school children with asthma and non-asthmatic schoolmates. Pediatrics 1979, 64:878-881.

24. Cook BA, Schaller $\mathrm{K}$, Krischer JP: School absence among children with chronic illness. J Sch Health 1985, 55(7):265.

25. Moonie S, Sterling DA, Figgs LW, Castro M: The relationship between school absence, academic performance, and asthma status. J Sch Health 2008, 78(3):140-148.

26. Colegrove RW, Huntzinger RM: Academic, behavioral, and social adaptation of boys with hemophilia/HIV disease. J Pediatr Psychol 1994, 19(4):457-473.

27. Thies KM: Identifying the educational implications of chronic illness in school children. J Sch Health 1999, 69:10.

28. Lynch EW, Lewis RB, Murphy DS: Educational services for children with chronic illnesses: perspectives of educators and families. Excep Child. 1992, 59:210-220.

29. Logan DE, Simons LE, Stein MJ, Chastain L: School impairment in adolescents with chronic pain. J Pain 2008, 9(5):407-416.

30. Fowler MG, Johnson MP, Welshimer KJ, Atkinson SS, Loda FA: Factors related to school absence among children with cardiac conditions. Am J Dis Child 1987, 141:1317-1320.

31. Weitzman M, Klerman LV, Lamb G, Menary J, Alpert JJ: School absence: a problem for the pediatrician. Pediatrics 1982, 69:739-746.

32. Billings AG, Moos RH, Miller JJ, Gottlieb JE: Psychosocial adaptation in juvenile rheumatic disease: a controlled evaluation. Health Psychol 1987, 6:343-359

33. Miller ML, Kress AM, Berry CA: Decreased physical function in juvenile rheumatoid arthritis. Arthritis Care Res 1999, 12(5):309-313.

doi:10.1186/1471-2431-13-2

Cite this article as: Bouaddi et al.: Impact of juvenile idiopathic arthritis on schooling. BMC Pediatrics 2013 13:2.

\section{Submit your next manuscript to BioMed Central and take full advantage of:}

- Convenient online submission

- Thorough peer review

- No space constraints or color figure charges

- Immediate publication on acceptance

- Inclusion in PubMed, CAS, Scopus and Google Scholar

- Research which is freely available for redistribution

Submit your manuscript at www.biomedcentral.com/submit
C Biomed Central 